\title{
Balancing Land Use Trade-Offs: The Role of Wilderness in Nature Conservation
}

\author{
Jason Irving
}

\section{Key Points}

- Creating wilderness areas is often perceived in the community as an exercise in 'saving' areas, which can lead to conflict and a perception that wilderness protection is inconsistent with achieving other outcomes. Placing wilderness in its context as a core component of protected area systems and the several roles it plays in that context can help alleviate this. It can also reinforce the principles of wilderness that need to be maintained, such as the need for large-scale, intact areas.

- Pragmatism is inevitably necessary to achieve large-scale wilderness designations or active management of other tenured lands to maintain or enhance wilderness values.

- The evolution of the role of protected area systems, and the concept of wilderness, is not well understood or discussed, and neither are the challenges and policy adaptations for the Australian context of wilderness. Addressing this into the future is essential for maintaining the relevance of wilderness in conservation planning. 
With over 20 years on the South Australian Wilderness Advisory Committee (WAC), which oversaw the creation of nearly 2 million hectares of wilderness protection areas, Rob Lesslie played a major role in promoting better understandings of the concept of wilderness, and applying it to protected area systems. The rapid growth in the wilderness estate between 2002 and 2012 led to land use trade-offs that were the subject of considerable debate. One of Rob's most powerful contributions was articulating how large wilderness areas could play a role in connecting natural areas and ecological processes across the landscape.

The South Australian Wilderness Protection Act 1992 provides for the protection of wilderness and restoration of land to its pre-European contact condition. Areas defined as 'wilderness' under the Act share certain features: the land and its ecosystems must not have been affected (or must have been affected to only a minor extent) by modern technology, and must not have been seriously affected by exotic animals or plants or other exotic organisms. In assessing areas for wilderness protection, these criteria are applied using the conceptual framework that Rob pioneered for the Australian Government's National Wilderness Inventory. Four indicators of wilderness quality are tested: remoteness from access, remoteness from settlement, apparent naturalness and biophysical naturalness. In this schema, wilderness is represented as a variable quality, which is entirely appropriate.

The Wilderness Protection Act established the WAC. ${ }^{1}$ The committee's function was to assess all land in South Australia for protection under the Act. The process for assessment-including reporting, public consultation and decision-making about whether an area of land should be protected under the Act-was mandated by the Act. Protected areas came under the control of the minister for environment and were managed by the director of National Parks and Wildlife, along with other national parks in South Australia.

The WAC had a mandate to assess all lands, regardless of tenure. It worked assiduously to assess existing conservation lands owned by government for their wilderness values, and made recommendations for some of these to change to wilderness areas. These areas were, by and large, intact; most were managed by government within a wilderness management framework.

1 The Wilderness Advisory Committee was abolished in 2015, but its functions were absorbed, unchanged, into the Parks and Wilderness Council under the National Parks and Wildlife Act 1972 (SA). 
Early gains on Kangaroo Island in 1993, whereby five wilderness protection areas were proclaimed-Cape Bouguer, Cape Gantheaume, Cape Torrens, Ravine des Casoars and Western River-were not repeated until 2004, when three wilderness protection areas were established on the Eyre Peninsula—at Hambidge, Hincks and Memory Cove. The Billiatt and Danggali Wilderness Protection Areas in the Murray Mallee were proclaimed in 2009, and islands along the west coast were assessed leading to the Investigator Group and Nuyts Archipelago Wilderness Protection Areas being proclaimed in 2011.

There was considerable debate over the land uses that should prevail in wilderness areas. Wilderness is a term with strong connotations. The perception that the land would be 'locked up', ultimately reverting to some 'primitive' long-gone state, prompted concerns about access for recreation and fire management. Compromises had to be reached. Proposals for Avoid Bay and Bascombe Well on the Eyre Peninsula, and Ngarkat in the Murray Mallee, were withdrawn in response to these kinds of concerns. Concerns about the trade-offs that local communities might have to make were largely addressed through explaining how the land would be managed into the future, and offering assurances that people's access to the land would remain fundamentally unchanged.

The 12 wilderness protection areas named above were declared with relatively minimal conflict - the trade-offs were low to non-existent. The areas were all existing no-mining parks with low visitor use, and they were already managed according to wilderness values; it was (without being cavalier) a case of changing the colour on the map from green to dark green. However, this was not the case when the WAC assessed two other conservation areas: Yellabinna and Nullarbor. In both these areas, exploration and mining were permitted within a conservation framework; therefore, it was necessary to consider how to deal with mining as a land use when determining areas that were suitable for wilderness protection.

In 2002, the South Australian Government made a pre-election policy commitment to establish a wilderness area in the Yellabinna wilderness. This vast area of mallee in the far west of the state is covered by over 3 million hectares of parks and reserves. The election commitment followed the previous government's reproclamation of the central portion of the Yumbarra Conservation Park to enable mineral exploration. In undertaking a wilderness assessment of Yellabinna-for the express purpose of identifying an area for protection-the WAC had to consider 
how to locate a wilderness boundary that would be acceptable to government and allow access for mining in an area that was considered an emerging mineral sands province.

The WAC's initial report established a set of principles for locating and designing a wilderness protection area in the Yellabinna wilderness. The committee called on the relevant government departments (environment and mining) to negotiate a location that met the principles of the report and minimised the impact of future mineral development. This approach proved highly successful. Despite the length of time it took to complete the negotiations, 500,000 hectares of land were eventually identified, which the WAC endorsed. An assessment report recommending the establishment of the Yellabinna Wilderness Protection Area was subsequently prepared, and the area was proclaimed in 2005.

This same process was applied to an assessment of the Nullarbor region. The Nullarbor National Park and Regional Reserve, which provided limited mining access, was assessed and a 900,000-hectare Nullarbor Wilderness Protection Area was established in 2013. This assessment had the added complexity of accommodating visitor access to scenic lookouts along the Nullarbor cliffs.

Both the Yellabinna and Nullarbor processes were highly effective; both relied, to some extent, on strong political commitments to achieve positive outcomes. The process devised by the WAC enabled government to make decisions about land use trade-offs using a set of predetermined principles; however, there was still a degree of conflict regarding these principles. The length of time it took to achieve wilderness protection areas in Yellabinna and Nullarbor caused interest in further wilderness areas to wane. The price of the success of these processes seemed to confirm the view that wilderness and mining were mutually exclusive; indeed, until 2002 , creating wilderness areas had nothing to do with mining, as mining was not allowed in conservation lands under assessment.

Wilderness was now at a crossroads. Viewed positively, there was an opportunity for the WAC to take stock of its achievements and consider its future directions. In considering its statutory function to assess all land in South Australia for its wilderness values, the committee considered that it had largely discharged its functions in the settled agricultural areas of the state. However, there were still large areas of the state that had not been assessed. In particular, the arid lands, which make up the 
majority of the state's landmass, were considered to contain substantial areas of land that would meet the wilderness criteria. Recognising the complexity of tenure and land use in the arid lands, the committee decided to undertake an audit, rather than launch into a new assessment. The committee understood that it was unlikely that a system of wilderness areas could be created in the arid zone, let alone an individual area, for the foreseeable future. It embarked on a process of discussion and debate, reviewed traditional approaches and considered new ways of protecting or managing wilderness. As it rethought the role of wilderness, the review process provoked lively discussions about principles versus pragmatism.

The resulting report, 'Measures for Improving Wilderness Protection in South Australia's Arid Lands', was completed in 2014. The report confirmed that there were areas of high wilderness value and potential national significance in the state's arid area. The diverse tenures in the area-pastoral leases, reserves under the National Parks and Wildlife Act 1972 and freehold Aboriginal land — prompted the committee to examine wilderness management holistically and to propose a range of measures to protect wilderness values across the vast area. The complex land use and management regimes in the arid lands included:

- management of land for sheep and cattle production

- conservation management by both government and non-government bodies

- land managed for Aboriginal cultural purposes and economic activity

- tourism, transport, defence and mineral and petroleum exploration and extraction.

Against this backdrop, and in consideration of climate predictions for the area, the WAC concluded that while formal protection under the Act remained the preferred means of wilderness protection, in circumstances in which the legislation was not practicable, additional protective mechanisms were required. These additional mechanisms included:

- working with pastoral leaseholders to improve the management of land recognised as having wilderness values, including promoting principles to minimise grazing impacts

- identifying and managing wilderness within parks through existing management plans, without the need to formally excise areas and dedicate them under the Wilderness Protection Act 
- providing for co-management with Aboriginal people of existing government-owned wilderness protection areas, and enabling the creation of wilderness areas on Aboriginal-owned land ${ }^{2}$

- developing mechanisms to work with Aboriginal people to protect wilderness values on their land.

In addition, the committee recommended that measures should be undertaken to recognise wilderness values in exploration and mining tenements, and to promote better understanding of the significance of arid wilderness and landscape-scale conservation. These recommendations serve as a starting point for further policy work on wilderness; considerably more work is required to translate them into action. The biggest challenge will be reframing wilderness and integrating it into existing and new conservation measures to better balance the perceived land use trade-offs that have become associated with protecting wilderness.

\section{Recommendations}

This chapter has raised several issues that warrant further consideration if wilderness is to play a role in contemporary land use planning for conservation outcomes. While the focus has been on South Australia, the issues have relevance nationally.

Wilderness needs to be integrated more fully into protected area methodologies and practices. While it sits comfortably on a spectrum of protected area management categories in the International Union for Conservation of Nature protected area management guidelines, it tends to sit separately in the minds of policymakers, protected area managers and others. As a starting point, it would be useful to examine how park policy managers and field managers perceive wilderness and its role in contemporary Australia.

Wilderness is sometimes perceived as a dated ideal-a 1970s concept about 'saving' areas; this 'saving' discourse often underpins campaigns to create new wilderness areas. It is necessary to reframe this discourse, casting wilderness itself in the role of saviour, for wilderness is critical to

2 This has since been enabled through amendments to the Wilderness Protection Act; the Nullarbor Wilderness Protection Area has a co-management agreement between the relevant minister and the native title holders. 
conserving intact natural areas for refugia and resilience in a changing climate. Affirming the role of wilderness areas as core protected areas to conserve nature efficiently could enable the benefits of such areas to be realised. However, reframing such a value-laden term is no easy matter. Different audiences will react differently; nowhere will this be more challenging and important than with Indigenous Australians, for whom wilderness principles and the injustices of terra nullius are linked.

There is merit in revisiting areas of land that were identified as wilderness areas of potential national significance, as these have driven many of the wilderness assessment priorities. Such a review could determine the current tenure status and wilderness quality of those areas (i.e. have their wilderness values been maintained or diminished?) and revisit the issue of potential national significance by asking new questions about their contribution to climate resilience as intact natural areas.

Finally, following the WAC's lead, it is important to remember that there is opportunity to find ways to leverage existing policy mechanisms, or create new ones, to achieve the protection and sympathetic management of wilderness values on lands where formal government-owned wilderness areas are neither practical nor possible. 
This text is taken from Land Use in Australia: Past, Present and Future, edited by Richard Thackway, published 2018 by ANU eView, The Australian National University, Canberra, Australia.

doi.org/10.22459/LUA.02.2018.07 